\title{
UN ÓLEO MEXICANO EN SANTIAGO DE COMPOSTELA
}

\section{Por José Rojas Garcidueñas}

Pensar, ahora, en la redacción de un catálogo de las pinturas mexicanas en el extranjero, es idea simplemente quimérica. Es muy probable que ese catálogo no se haga nunca, pero sí es posible ir compilando datos que, unidos y coordinados, a su debido tiempo, puedan dar idea bastante de la cantidad y de las proporciones de nuestra pintura que está fuera de México, así como de las épocas en que aume,ntaron o disminuyeron tales exportaciones y de los géneros y calidades de ellas.

Tal vez la mejor manera de iniciar las listas que algún día puedan formar aquel catálogo, sea por agrupamientos temáticos $\mathrm{y}$, entre ellas, ya puede considerarse que la relativa a imágenes guadalupanas va progresando por buen camino, gracias a las notas de diversos investigadores.

El primer lugar, en esa tarea, lo tiene, sin disputa el señor Joaquín González Moreno cuya Iconografia Guadalupana, en su primer tomo, único hasta hoy publicado, 1 registra 50 óleos firmados por pintores mexicanos bien identificados; aunque seguramente otra buena cantidad de obras serán también mexicanas, entre las cuatro o cinco de firmas desconocidas y el gran número de obras sin firmar, todas las cuales están cuidadosamente enumeradas en su magnífico catálogo de 303 fichas. Cabe advertir que la casi totalidad de las pinturas anotadas por el señor González Moreno se conservan en lugares de Andalucía.

Por otra parte, estos Anales han tenido la suerte de recibir diversas notas de investigadores extranjeros, que nos honran con sus colaboraciones. Así la referencia a una guadalupana de José de Alcíbar, que se conserva en Cuzco ${ }^{2}$ y, más tarde, el señor López Jiménez encontró dos guadalupanas en Murcia, una de Miguel Cabrera y otra de Arellano. ${ }^{8}$

1 Joaquín González Moreno. Iconografia Guadalupana. Clasificación cronológica y estudio artístico de las más notables reproducciones de la Virgen de Guadalupe de Méjico conservadas en las Provincias Españolas. Tomo I, Editorial Jus, México, 1959.

2 José de Mesa y Teresa Gisbert. "Pinturas mexicanas del siglo xvi en Perú y Bolivia", en Anales del Instituto de Investigaciones Estéticas, núm. 28, México, 1959.

3 José Crisanto López Jiménez. "Pinturas Mexicanas en Murcia y un triptico murciano de Nuestra Señora de Guadalupe", en Anales del Instituto de Investigaciones Estéticas, núm. 32, México, 1963. 
Recientemente salió a luz el muy interesante estudio sobre el arte barroco español de nuestro colega Francisco de la Maza, ${ }^{4}$ y allí encontramos referencias concretas a no menos de 10 óleos mexicanos con imágenes de la Virgen de Guadalupe, más otra de plumas, piezas que se encuentran en Salamanca (p. 92), otras en Segovia, Madrid y Toledo (pp. 99 y 100), dos en Córdoba (p. 141) y otra en Cabra (p. 172).

Por mi parte, considero una suerte poder añadir otra papeleta a esa ya importante lista.

En octubre de 1969 me fue dado visitar la hermosa catedral de Santiago de Compostela y allí, en sitio de honor, pues está presidiendo la Sala Capitular, encima del sitial del Prelado, encontré una muy buena pintura mexicana: es un óleo sobre lámina, de 22 x 15 centímetros aproximadamente (probablemente las medidas reales sean dos o tres centímetros más que las mencionadas, pues éstas fueron tomadas sin retirar la pintura del rico marco de plata que la encuadra que parece, también de factura mexicana). Representa a la Virgen de Guadalupe, del Tepeyac, con las cuatro apariciones de la misma, en los ángulos. Está firnıada: "Fct. J. Patricio Morlete Ruiz".

De este pintor, contemporáneo y discípulo de Miguel Cabrera, dice Manuel Toussaint: "Un pequeño número de artistas parece agruparse en torno del maestro cuando éste publicó su folleto acerca de la Guadalupana [Maravilla Americana y conjunto de raras maravillas. México, Imp. del Real y más antiguo Colegio de San Ildefonso, 1756.], pues unos intervienen en el examen del cuadro y todos dan su opinión..." Entre los de ese grupo menciona a Morlete y, líneas adelante, concretamente se refiere a él: "Don Juan Patricio Morlete Ruiz. Sabemos que nació en 1715; se casó muy joven con doña María Careaga, de quien tuvo muchos descendientes. La figura de este artista, en extremo simpática, coincide con sus obras, dotadas de una discreción rara en su época; aunque no pueda independizarse de ella, prefiere los tonos grises plateados en que se destaca la morbidez de los rostros... Sus obras no son muy abundantes; citemos los retratos de los virreyes Amarillas, Cajigal y Croix, que existen en el Museo de Historia de Chapultepec". 5 A lo anterior sólo hay que añadir que Toussaint olvidó recoger el dato que,

4 Francisco de la Maza. Cartas barrocas desde Castilla y Andalucia. Instituto de Investigaciones Estéticas, UNAM, México, 1963.

5 Manuel Toussaint. Arte Colonial en México. UNAM. Instituto de Investigaciones Estéticas. 2" edición, México, Imprenta Universitaria, 1962, pp. 172 y 173. 


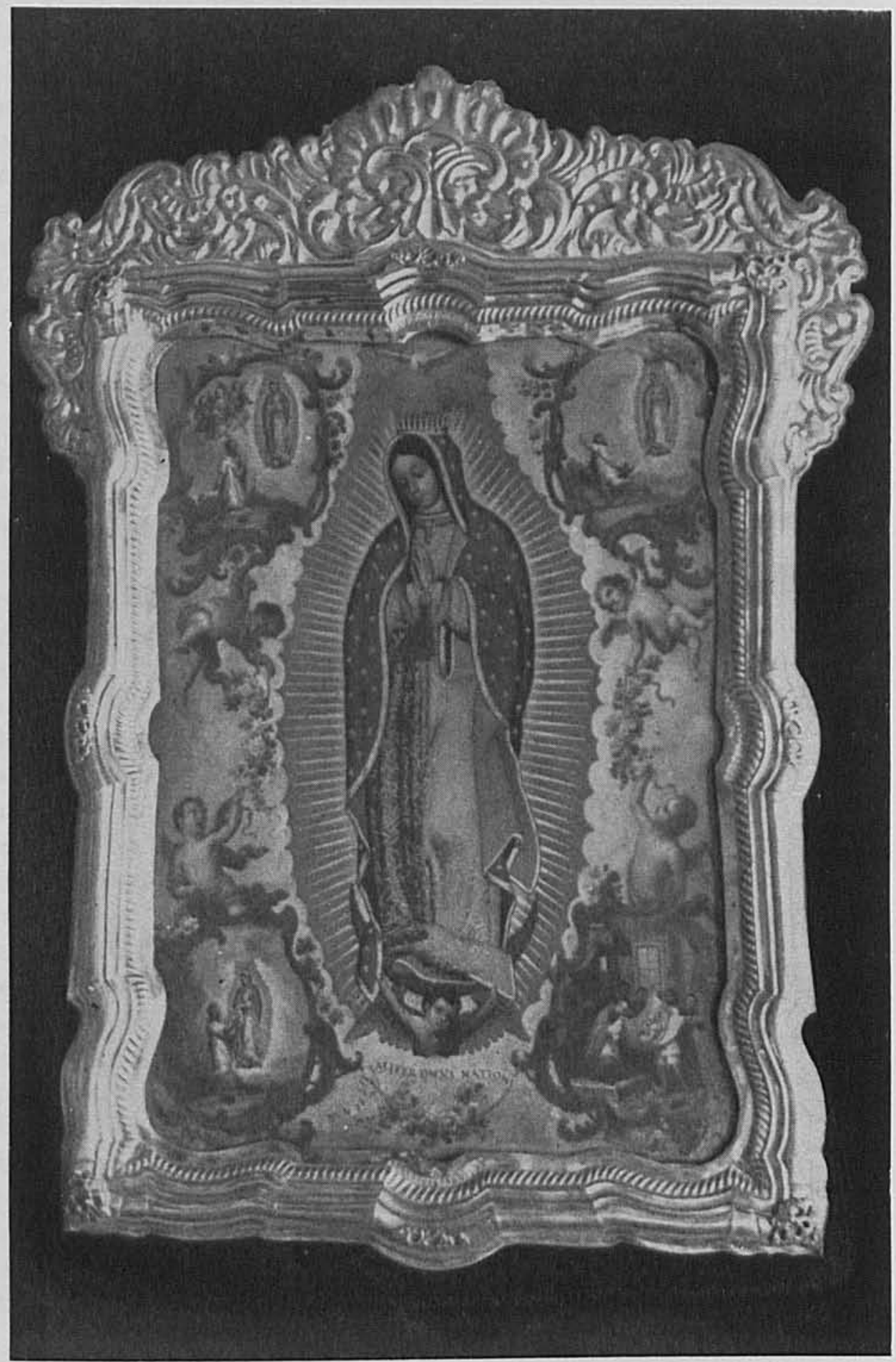

La Virgen de Guadalupe, de México, con las cuatro escenas de sus apariciones. Óleo sobre lámina por J. Patricio Morlete Ruiz, en la Sala Capitular de la Catedral de Santiago de Compostela. 
DOI: http://dx.doi.org/10.22201/iie.18703062e.1965.34.802 
años antes, había dado De la Maza, de que Morlete Ruiz nació en San Miguel el Grande (hoy San Miguel Allende, Guanajuato.) ${ }^{\circ}$

La Virgen de Guadalupe, que hoy está en la "Catedral Vieja" de Santiago, es obra de gran finura y delicadeza. El dibujo es muy bueno; el colorido un tanto dulzón, como el de todos los pintores de su tiempo, pero discreto, con esa general tendencia al predominio de los azules y rojos suaves, a las carnaciones rosadas, a lo "bonito" de la escuela de Cabrera, cuyos origenes están en ciertas características de Murillo que sus discípulos llevaron a la degeneración. La composición está cuidadosamente equilibrada.

Tantas veces hemos visto ese tema tratado de igual modo: la Virgen en el eje vertical y las cuatro escenas de las apariciones ocupando los ángulos, que al encontrarlo nuevamente se tiende a echar una rápida ojeada para comprobar que allí está algo tan conocido que no hay para qué fijarse en ello. Pero esta vez, al encontrar inesperadamente en tan lejano sitio esa pintura guadalupana, tuve la impresión de que habia alli un caso de esa curiosa persistencia de formas que ocurre, en la historia del arte, a través de tantas sucesivas modalidades de temas y significados, que acaban por transformarse en grado sumo pero que, al mismo tiempo, siguen conservando claros rasgos de su origen, a pesar de que el ejemplo moderno parezca ya no tener conexión alguna con su remota raíz. Tal vez fue la "saturación" - por decirlo así-, de arte románico en que me encontraba, en esos días de mi estancia en Santiago de Compostela, pero, cualquiera que haya sido la causa, el hecho es que al fijarme en la lámina dieciochesca y mexica. na, me percaté de la analogía de su composición con las del Cristo Pantocrator tan reiteradas en el arte románico: el Cristo en medio de la mandorla rodeado por el tetramorfos. Claro que, en este caso, en vez del adusto Pantocrator, sentado, que en su mano izquierda sostiene al mundo y con la derecha ritualmente bendice, aquí está, de pie, la Virgen de suaves líneas, con las manos juntas y la cabeza suavemente inclinada, y el tetramorfos no lo es propiamente, porque no están los símbolos de los cuatro evangelistas, sino que en la pintura de Morlete son cuatro escenitas de miniatura barroca, pero el hecho es que algo queda - el fondo oscuro detrás de la Virgen es una mandorla, las cuatro apariciones están situadas como el tetramorfos-, algo persiste, como el recuerdo, acaso subconsciente, que a través de seis siglos aflora en nuevas formas y con diferente sentido.

6 Francisco de la Maza. Revista Diuulgación Histórtica, vol. II, núm. 12, México, octubre de 1942, p. 619. 
Esas nuevas formas, en el óleo de Morlete Ruiz (aparte de la Virgen que, lógicamente, sigue el original del siglo xvi), son ya francamente rococó, sobre todo en los marcos de las escenas de las apariciones y en Ios encantadores angelillos que, sin el menor respeto al asunto devoto del cuadro, juegan con guirnaldas de rosas haciendo piruetas como chiquillos en un columpio.

De un barroquismo más contenido es el rico marco de plata que encuadra la pintura, pero en su remate también se perciben formas de un rocaille que apenas asoma, como indicando un momento de transición entre dos estilos sucesivos.

"No son muy abundantes" las obras de Morlete Ruiz decía, con razón, Toussaint. Por eso mismo creo que es pertinente dejar aquí registrada esa lámina, delicada y graciosa, que salió de aquel pincel, hoy conservada en perfecto estado y con evidente aprecio, en la catedral compostelana.

Finalmente, quiero aquí reiterar las gracias al señor Héctor Castro, quien ha tenido la gentileza de obtener y enviarme la fotografía que aquí se reproduce; con mi agradecimiento por tal servicio-que lo es para el arte mexicano- repito las gracias por la gentileza y pericia al mostrarnos la espléndida catedral y toda su amada ciudad de Santiago de Compostela. 